\title{
Comparison of Nano Particle Size Distributions by Different Measurement Techniques
}

\author{
Min-Suk Bae and Joon-Seok Oh'1)* \\ Atmospheric Sciences Research Center, University at Al bany, \\ State University of New York, Albany, New York, USA \\ ${ }^{1)}$ Division of Business, School of Business \& Economy, \\ Sook Myung Women's U niversity, Seoul, Korea
}

(Received 16 March 2009, revised 23 July 2009, accepted 20 August 2009)

\begin{abstract}
Understanding the Nano size particles is of great interest due to their chemical and physical behaviors such as compositions, size distributions, and number concentrations. Therefore, accurate measurements of size distributions and number concentrations in ultrafine particles are getting required because expected losses such as diffusion for the instrument system from ambient inlet to detector are a significant challenge. In this study, the data using the computed settling losses, impaction losses, diffusion losses for the sampling lines (explored different sampling line diameters, horizontal length, number of bending, line angles, flow rates with and without a bypass), and diffusion losses for the Scanning Mobility Particle Sizers are examined. As expected, the settling losses and impaction losses are very minor under $100 \mathrm{~nm}$, however, diffusion loss corrections for the sampling lines and the size instrument make a large difference for any measurement conditions with high numbers of particles smaller mobility size. Both with and without the loss corrections, which can affect to size distributions and number concentrations are described. First, $80 \%$ or more of the smallest particles (less than $10 \mathrm{~nm}$ ) can be lost in the condition of a flow rate of 0.3 liter per minute and the length of sampling line of $1.0 \mathrm{~m}$, second, total number concentrations of measurements are quite significantly affected, and the mode structure of the size distribution changes dramatically after the loss corrections applied. With compared to the different measurements, statistically diffusion loss corrections yield a required process of the ambient particle concentrations. Based on the current study, as an implication, a possibility of establishing direct revelation mechanisms is suggested.
\end{abstract}

Key words : SMPS, CPC, Diffusion losses

\section{INTRODUCTION}

Size concentration of atmospheric aerosol has recently been an active research topic in a variety of

\footnotetext{
* Corresponding author.

Tel : +82-2-2077-7378, E-mail : joon5@sookmyung.ac.kr
}

locations including rural and urban areas (Woo et al., 2008; Qian et al., 2007; Jeong et al., 2006; Watson et al., 2006, Kim and Ahn, 2005). Measurement of size distributions inclusive of particles in the $3 \sim 100$ nanometer $(\mathrm{nm})$ size range, while always important and of interest, has gained increasing attention due to the role of nanoparticles in aerosol formation and 
growth, in manufacturing and nanotechnology, and in human health effects, to name a few (Park et al., 2009; Lee et al., 2006; Dal Maso et al., 2005; Jeong et al., 2004; Kulmala et al., 2004; Stanier et al., 2004). In most studies, the aerosol size distributions and total number concentrations have been measured using a Scanning Mobility Particle Sizer (SMPS) and a Condensation Particle Counter (CPC), respectively. The SMPS instrument is commonly used for measuring aerosol particles with diameter less than $20 \mathrm{~nm}$ (Lee et al., 2008; Watson et al., 2008; Hogrefe et al., 2006).

However, measuring as particles these entities that consist of as few as a couple of molecules as particles is a significant challenge in terms of detection sensitivity. In conditions in a flowrate of less 1.0 liter per minute $(1 \mathrm{pm})$, particle losses such as diffusion can be expected, need to be considered. This note addresses a post-measurement correction that has been applied to particle size distributions measured with Scanning Mobility Particle Sizers (SMPS). The science behind the correction is not new application-it has been described numerous times (Wang et al., 2002; Brockman, 2001; Hinds, 1982; Gormley and Kennedy, 1949). Even though the loss processes and correction algorithms for particle measurement systems are well-known and established in many circles, as size distribution measurements have become more common, and are being made to smaller and smaller particle diameters, data sets are being published and archived that do not account for particle losses in the sampling systems. These losses grow exponentially, and become very important below roughly $20 \mathrm{~nm}$. Accounting for these losses by applying a post processing correction can lead to dramatic changes in the final reported concentrations and size distributions in environments with large concentrations of particles with mobility diameters of less than $20 \mathrm{~nm}$.

Each measurement technique and instrument has inherent limitations. While some of the physical processes responsible for these systematic errors are complicated and require a substantial effort to be quantified, others can be evaluated by simpler means and the measurements adjusted accordingly. Inlet and sample line diffusion loss is an example of the latter, caused by particle deposition onto sample line and instrument surfaces. Particle losses due to diffusion are more pronounced at lower flow rates and for smaller particles.

Diffusion losses will most often have a greater impact on the measured concentration. Such diffusion losses in the SMPS have been observed in experiments conducted with polydisperse $\mathrm{NaCl}$ aerosol in laboratory conditions (Frank et al., 2008), losses are shown to occur in various parts of the Electrostatic Classifier. Other investigators have also found significant diffusion losses occurring within the Differential Mobility Analyzers (DMA), a part of the SMPS (Rodrigue et al., 2007; Reineking and Porstendörfer, 1986).

A diffusion loss correction for the TSI SMPS has recently been determined (TSI, Inc. 2006), which is intended to compensate for diffusion losses in the SMPS for particles with diameters less than $100 \mathrm{~nm}$. These diffusion losses are characterized in terms of total penetration, which is the product of the penetration for five composite flow paths through the SMPS: impactor inlet, bi-polar neutralizer and the internal plumbing, the tubing to the DMA and Condensation Particle Counter (CPC), the DMA itself, and the CPC (including penetration inside the CPC, activation and optical detection efficiencies and CPC inlet losses). The diffusion loss correction also compensates for the effect of diffusion losses on the determination of the SMPS mean particle size, causing it to shift towards smaller particle sizes (Frank et al., 2008). In order to address these concerns, with and without diffusion loss corrections by the sampling lines and the SMPS, particle number concentrations and size distributions are recalculated and compared to Fast Mobility Particle Sizer Spectrometer (FMPS), and n-butyl alcohol based CPC (CPC 3025).

\section{EXPERIMENTAL METHODS AND DATA ANALYSIS}

\subsection{Aerosol generation chamber system}

A schematic of the generation system for aerosols is shown in Fig. 1. One of the aerosol-generation in- 
[Setup 01] Aerosol Generation Chamber System
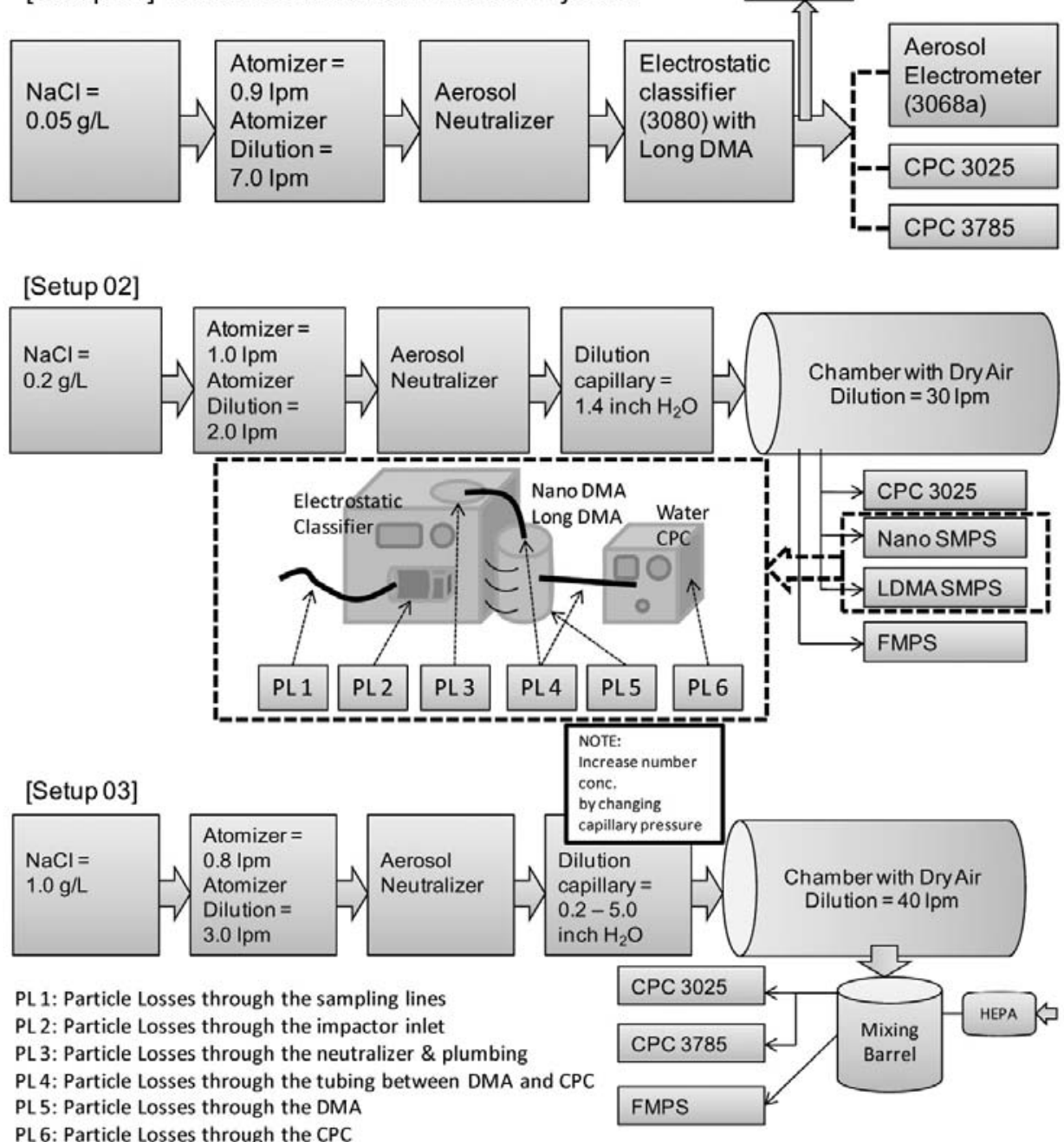

Fig. 1. Schematic of the generation system for comparison of the selected size concentration in the range of 15 $90 \mathrm{~nm}$ to test the sensitivities of $n$-butyl alcohol based CPC (CPC 3025) and water based CPC (CPC 3785) [Setup 01]. Schematic of the generation system for aerosols for the size distribution comparison of the Nano and Long DMA Scanning Mobility Particle Sizer (Nano SMPS and LDMA SMPS) spectrometer related to the positions of Particle Losses (PL), Fast Mobility Particle Sizer (FMPS) spectrometer, and n-butyl alcohol based CPC (CPC 3025) [Setup 02]. Schematic of the generation system for aerosols for the total number concentration comparison of n-butyl alcohol based CPC (CPC 3025), water based CPC (CPC 3785), and FMPS [Setup 03].

struments utilized is a constant output atomizer (TSI Model 3076) operating in the recirculation mode. Droplets are produced by atomizing a solution of $\mathrm{NaCl}$ in this study. The generated aerosol is mixed with a dry airflow, which leads to its dilution and partial evaporation of the solution. The aerosol passes through an aerosol neutralizer (TSI Model 3054) following by a dilution capillary, and then enters a dilution chamber system. Three different setups are operated. 
Table 1. Flow description of the Nano and Long DMA Scanning Mobility Particle Sizer (Nano SMPS and LDMA SMPS) and n-butyl alcohol based CPC (CPC 3025).

\begin{tabular}{llcc}
\hline & & Sheath flow (lpm) & Inlet flow (lpm) \\
\hline Nano SMPS $^{(1)}$ & Electrostatic Classifier 3080 & 3.0 & 0.3 \\
& Water CPC (CPC 3785) & & $1.0^{(3)}$ \\
LDMA SMPS $^{(2)}$ & Electrostatic Classifier 3080 & 3.0 & 0.3 \\
CPC & Water CPC (CPC 3785) & & $1.0^{(3)}$ \\
FMPS & n-butyl alcohol CPC (CPC 3025) & 40.0 & 1.5 \\
\hline
\end{tabular}

${ }^{(1)}$ TSI 3081 Long DMA. ${ }^{(2)}$ TSI 3085 Nano DMA. ${ }^{(3)}$ Flow includes 0.7 lpm of make-up-air

At the first setup, to analyze a selected aerosol size for testing n-butyl alcohol based CPC (CPC 3025) and water based CPC (CPC 3785), the polydisperse aerosol flow is directed into an Electrostatic Classifier (TSI 3080) with a Long Differential Mobility Analyzer (LDMA TSI Model 3081) prior to entering the Aerosol Electrometer (TSI 3068a) and two CPCs. Polydisperse aerosol particles pass through a charger and then are separated in the DMA according to their electrical mobility. The DMA voltage and the aerosol flow are adjusted so that particles of a preselected size range (from 15 to $90 \mathrm{~nm}$ in this study) leave the DMA. To reduce relative humidity, which can affect the mean size of the dry aerosol distribution, the sheath flow has a Drierite column. Once preselected size looks stabilized, air-outlet of electrostatic classifier is connected to Aerosol Electrometer 3068a, nbutyl alcohol based CPC (CPC 3025), and water based CPC (CPC 3785) in order to capture the concentrations.

The second setup is the condition for a targeted number concentration to compare the size distribution of the Nano and Long DMA Scanning Mobility Particle Sizer (Nano SMPS and LDMA SMPS) spectrometer related to the positions of Particle Losses (PL), Fast Mobility Particle Sizer (FMPS) Spectrometer, and n-butyl alcohol based CPC (CPC 3025).

The last setup is the condition for a variable number concentration controlled by a capillary pressure to compare the total number concentrations of nbutyl alcohol based CPC (CPC 3025), water based CPC (CPC 3785), which is a part of the SMPS, and FMPS. During the analysis, the flow rates of instruments are checked by a flow reader.
Typically the SMPS components are an Electrostatic Classifier, Nano or Long DMA (LDMA) and a CPC. The SMPS is operated with a sheath flow and a sample flow rate of generally less $1.0 \mathrm{lpm}$ (Frank et al., 2008; Desantes et al., 2005). A bypass flow (around $5.0 \mathrm{lpm}$ ) is also available to reduce diffusion losses by the sampling lines. The target aerosol size ranges are about $2 \sim 168 \mathrm{~nm}$ for the Nano SMPS and $5 \sim 830 \mathrm{~nm}$ for the LDMA SMPS depending on a size of selected orifice in the sampling inlet. Neutralizers used within Electrostatic Classifiers have an intensity of $10.0 \mathrm{mCi}$. Measurements of particle number concentrations and size distributions using two different Scanning Mobility Particle Sizers (SMPS). In this study, the Nano (TSI Model 3085) DMA SMPS components are an Electrostatic Classifier (TSI Model 3080) and a water based CPC (TSI Model 3785). The SMPS inlet flow is $0.3 \mathrm{lpm}$ with $3.0 \mathrm{lpm}$ sheath flow. Long (TSI Model 3081) DMA SMPS components are an Electrostatic Classifier (TSI Model 3080) with the same water based CPC (TSI Model 3785) as same as Nano SMPS flow settings (Table 1). Data used for analysis are 3-min averages.

The FMPS (TSI Model 3091, a flow rate of 10.0 $\mathrm{lpm})$ which measures submicrometer aerosol particles from 5.6 to $560 \mathrm{~nm}$ with one-second resolution are operated to compare the Nano SMPS and LDMA SMPS spectrometer related to the particle diffusion losses. The benefit of FMPS is to safely ignore the diffusion losses due to its high flow rate $(10 \mathrm{lpm})$ with particle-free sheath air (40 lpm). A n-butyl alcohol based CPC (CPC 3025) is operated to compare the total number concentrations in this study. 


\subsection{Diffusion loss correction for the sampling lines and the SMPS}

Sample line diffusion loss caused by particle deposition onto sample lines is expected. In order to estimate the diffusion losses in the sampling lines, an equation for circular tube penetration efficiency for aerosols can be derived as function of $D$ (the paricle diffusion coefficient), $L$ (the length of the sampling lines), and $Q$ (the volume flow rate through the sampling lines) (Hinds, 1982).

Diffusion loss for the SMPS can be caused due to attractions between molecules and surfaces. Smaller particulate matters $(<100 \mathrm{~nm})$ have higher losses due to diffusion. Thus, diffusion losses by the wall of sampling lines or the SMPS system itself are inevitable during the sampling. Since the SMPS measures in the size range from around $3 \mathrm{~nm}$, diffusion loss correction should be applied.

Fig. 1 presents the Schematic of the component Scanning Mobility Particle Sizer (SMPS) spectrometer related to the positions of Particle Loss (PL). PL 1, described above, indicates the diffusion losses for the sampling lines, PL 2 presets the diffusion losses related to the SMPS impactor depending on the Reynolds number (function of the flow rate and the gas properties of the working gas), and PL 3, PL 4, PL 5, \& PL 6 show bi-polar neutralizer (function of the particle diffusion coefficient and each instrument specified flow rate), the connecting tubing, the Differential Mobility Analyzers (DMA), and the efficiency of the CPC with diffusion losses, respectively (TSI, Inc., 2006; Chen et al., 1998; Birmili et al., 1997; Reineking et al., 1986).

\section{RESULTS AND DISCUSSTION}

There are several mechanisms that can cause particle losses in a sampling system we need to consider. These include the size-dependent sampling efficiency of the inlet and deposition within the sampling lines that transport particles to the measuring instruments. Mechanisms by which an aerosol particle can be deposited onto the wall of a sampling line include: interception, inertial impaction, diffusion, gravitatio- nal settling, thermophoresis, electrostatic attraction, and others. During the sampling, particle losses related to settling, impaction, and diffusion could be the most. Fig. 2 presents that estimated losses for the size of under $100 \mathrm{~nm}$ caused by settling and impaction can be safely neglected. However, it is very important that when a sampling is performed for the $\mathrm{PM}_{10}$, these losses are not insignificant, should be considered.

Fig. 3 shows the percent of diffusion losses for the sampling lines, which are depending on the particle diameter (nm), length of sampling line ( $\mathrm{m}$ ), and flow rate (lpm). To explore the large realms of the diffusion losses for the sampling lines, under several conditions, the diffusion losses are examined. (1) Diameters are chosen from $8.35 \sim 96.5 \mathrm{~nm}$, (2) the length of sampling lines are from $0.2 \sim 5.0 \mathrm{~m}$, and (3) the flow rate of 0.3 and $0.6 \mathrm{lpm}$ are selected in the condition with and without the bypass of $5.0 \mathrm{lpm}$. In this study, applying the correction to the very smallest size bins (below $8 \mathrm{~nm}$ ), which produced sporadic and noisy data with unrealistic extreme values, are avoided both the diffusion loss calculations for the sampling lines and the SMPS.

The right panels of Fig. 3 show diffusion losses for the sampling lines in the condition of the bypass of $5.0 \mathrm{lpm}$ for the SMPS. Total averages of the diffusion losses for the sampling lines yield less 5\% losses (sampling lines of less $1.0 \mathrm{~m}$ ), so these diffusion losses in the sampling lines could be inconsiderable for total aerosol nanoparticle number concentrations. However, without the bypass, since the diffusion losses are size dependant, the smaller particle presented the more susceptible it is to diffusion (up to $28 \%$ and $19 \%$ diffusion losses in the size bin of $8.35 \mathrm{~nm}$ with the flow rate of 0.3 and $0.6 \mathrm{lpm}$, respectively). It is very important that these amounts of particle losses cannot be ignored when sizing nanoparitcle aerosols.

The effects of the diffusion correction on the data sets are presented below, all data used has been recalculated with the updated software to compensate for diffusion losses (in addition to the standard multiple charging correction). The diffusion losses of aerosol size distributions from particle counts recorded during SMPS measurements can be described in terms 
Settling Losses in the Sampling Lines (\%)
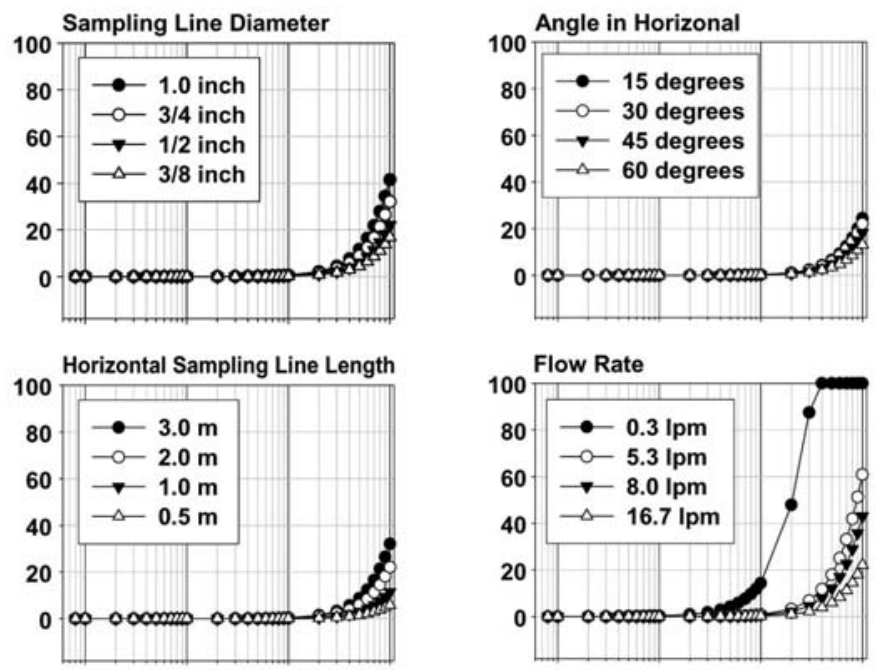

Impaction Losses in the Sampling Line (\%)
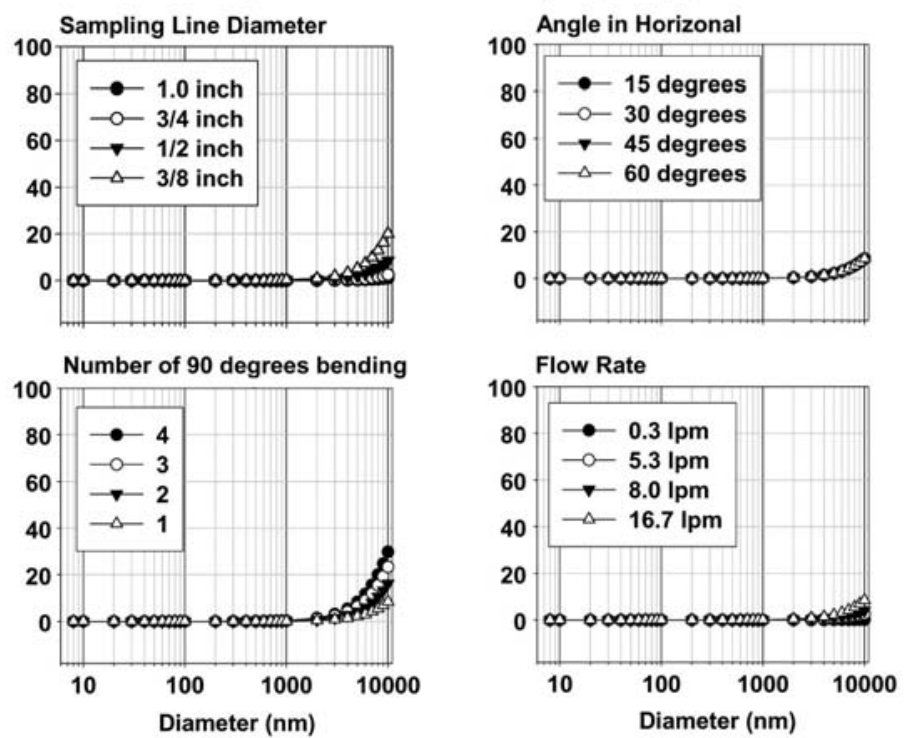

Fig. 2. Computed settling losses and impaction losses in the sampling line. (Note: fixed parameters are Sampling Line Diameter of 1/2 inch, Horizontal Length of 2.0 meter, Number of 90 degrees bending of 1.0, Sampling Line Angle in horizontal of 30 degree, and Flow Rate of 16.7 lpm).

of the instrument empirical diffusion losses, which operationally produces the reported number of particles in a given bin without the diffusion losses calculated and with the diffusion losses calculated. That is, the empirical diffusion losses are given by the ratio of without and with the diffusion loss corrections by the TSI software.

In Fig. 3 we present the empirical diffusion losses by percent for the SMPS, and they can be the diffusion loss correction (DLC) factors themselves. These 

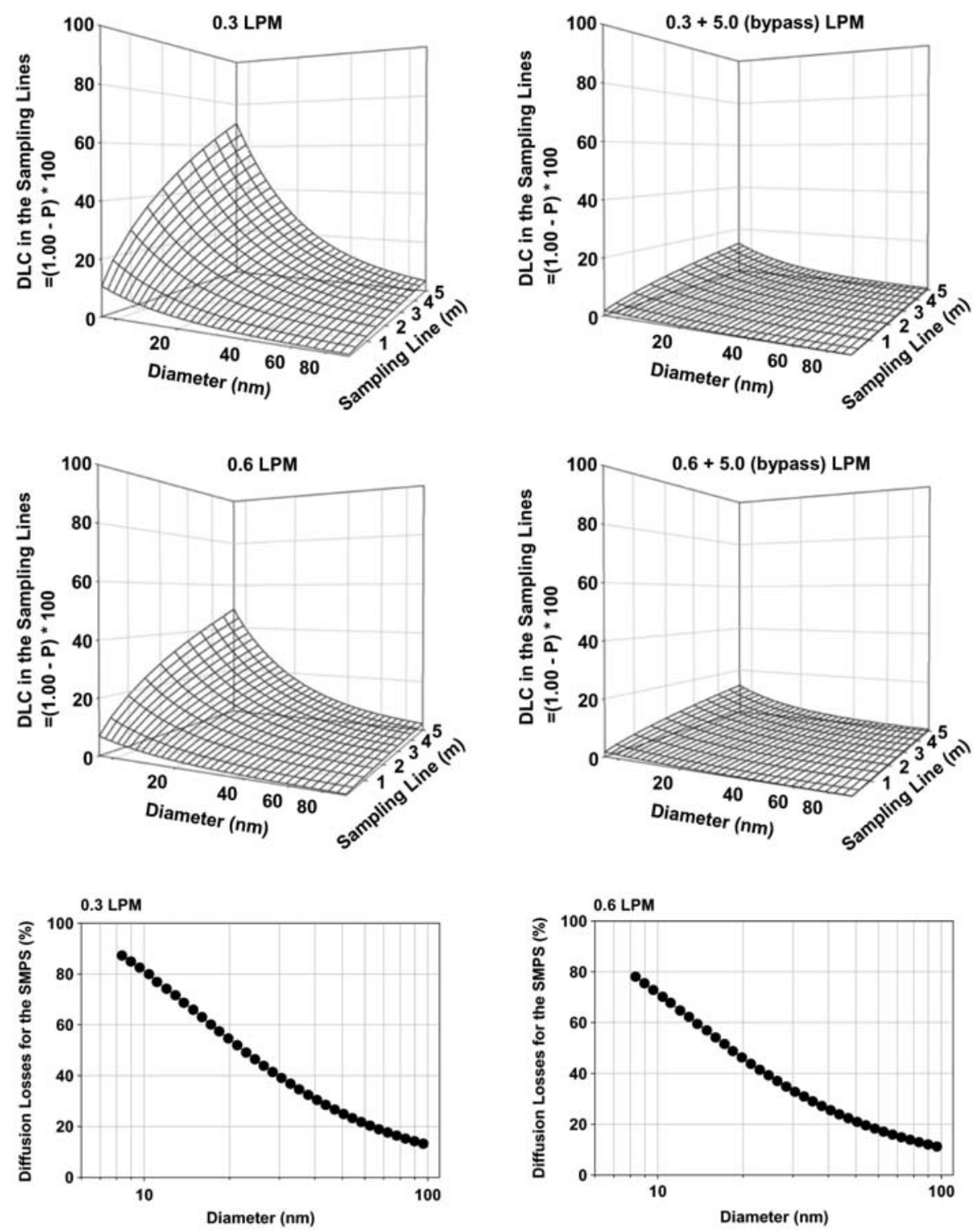

Fig. 3. Diffusion Losses for the Sampling Lines and the Scanning Mobility Particle Sizer (SMPS) [Note: DLC=Diffusion Loss Correction].

percents in Fig. 3 are computed for each flow rate of 0.3 and $0.6 \mathrm{lpm}$. Any increase in the DMA sample flow means a larger fraction of the particles in the sample are being detected due to reduction of diffusion losses by virtue of a reduced residence time. Fig. 3 shows the percent for the diffusion loss correc- tion only to the empirical diffusion loss. For our conditions, the diffusion correction is $12 \sim 15 \%$ at $100 \mathrm{~nm}$, increases to about $45 \sim 55 \%$ at $20 \mathrm{~nm}$, then increases rapidly with decreasing diameter, reaching values at the lowest reported mobility diameters of almost $78 \%$ and $87 \%$ for SMPS flow of 0.6 , and 0.3 

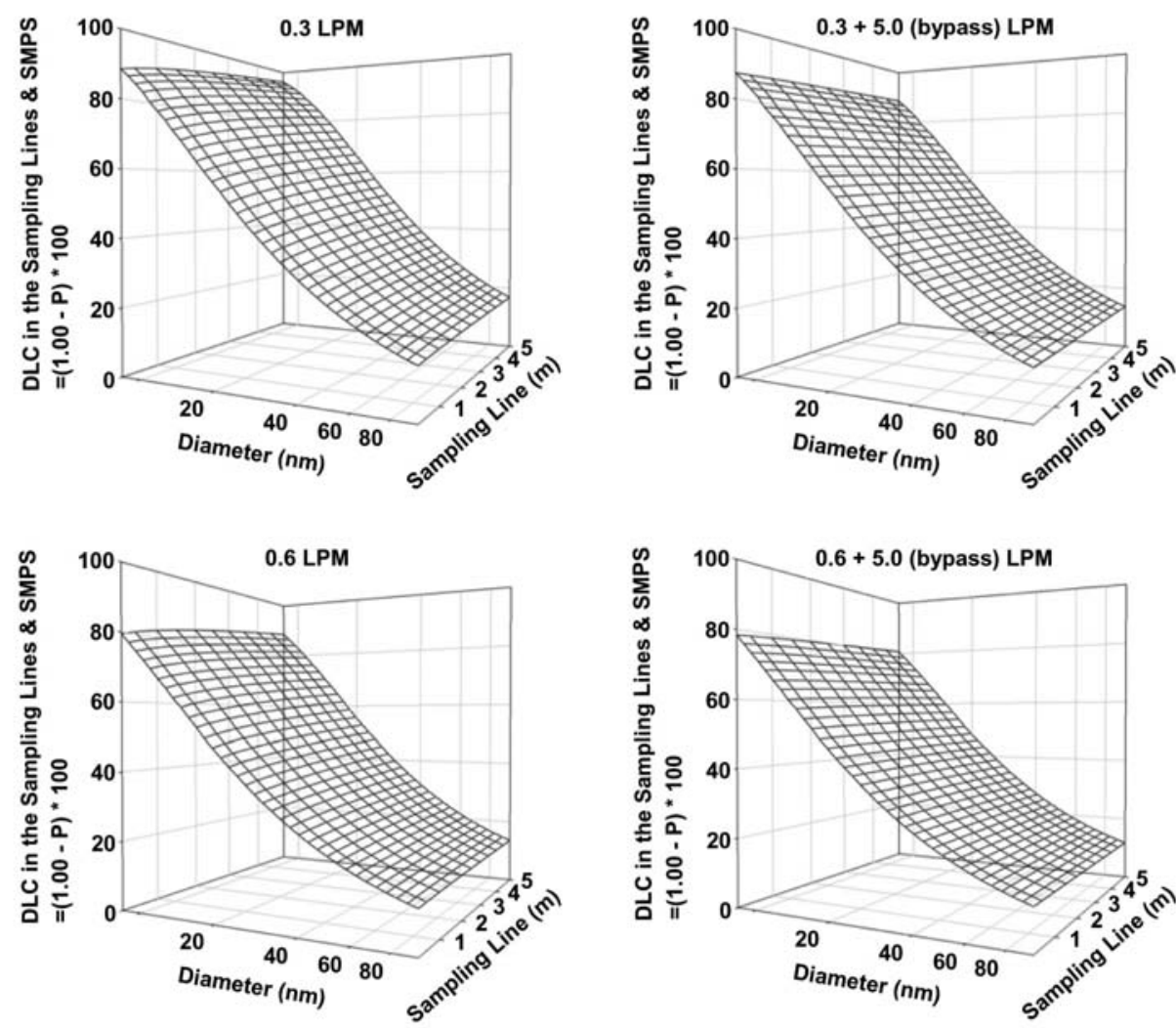

Fig. 4. Combined Diffusion Losses for the Sampling Lines and the Scanning Mobility Particle Sizer (SMPS) [Note: DLC=Diffusion Loss Correction].

lpm, respectively.

As described above, the rapidly increasing diffusion correction presents a dilemma for those trying to obtain size distributions for particles down to very small sizes. Clearly the correction is necessary to produce reliable data for sizes on the order of $20 \mathrm{~nm}$ or smaller. However, again, applying the correction to the very smallest size bins (below $8 \mathrm{~nm}$ ) produced sporadic and noisy data. It causes single count in the smallest size bins get tremendously over emphasized resulting in unrealistic particle size distributions. We compromised by only considering sizes above $8 \mathrm{~nm}$, which unfortunately required excluding data for smaller size bins.

Fig. 4 shows the combined diffusion losses for the sampling lines and the SMPS (Fig. 3). The diffusion losses for the sampling lines indicate relatively small increments of losses of total, without the bypass, the smaller particle presented the $19 \sim 28 \%$ in the size bin of $8.35 \mathrm{~nm}$. These changes will certainly impact both the mode and number concentrations when particle nucleation and growth events occur.

As a result, the diffusion correction is certainly required, for example, amount of $91 \%(8.35 \mathrm{~nm})$, $85 \%(10.4 \mathrm{~nm}), 58 \%(21.3 \mathrm{~nm}), 34 \%(40.7 \mathrm{~nm}), 23 \%$ $(62.6 \mathrm{~nm})$, and $15 \%(96.5 \mathrm{~nm})$ with a condition of $0.3 \mathrm{lpm}$ and the length of sampling line of $1.0 \mathrm{~m}$.

Before comparing the size distributions affected by the diffusion loss correction, we need to independently compare sized aerosols and total number concentrations by Aerosol Electrometer 3068a, n-butyl alcohol based CPC (CPC 3025), water based CPC (CPC 3785), and FMPS to see their good agreement in a range of concentrations. 
(a)
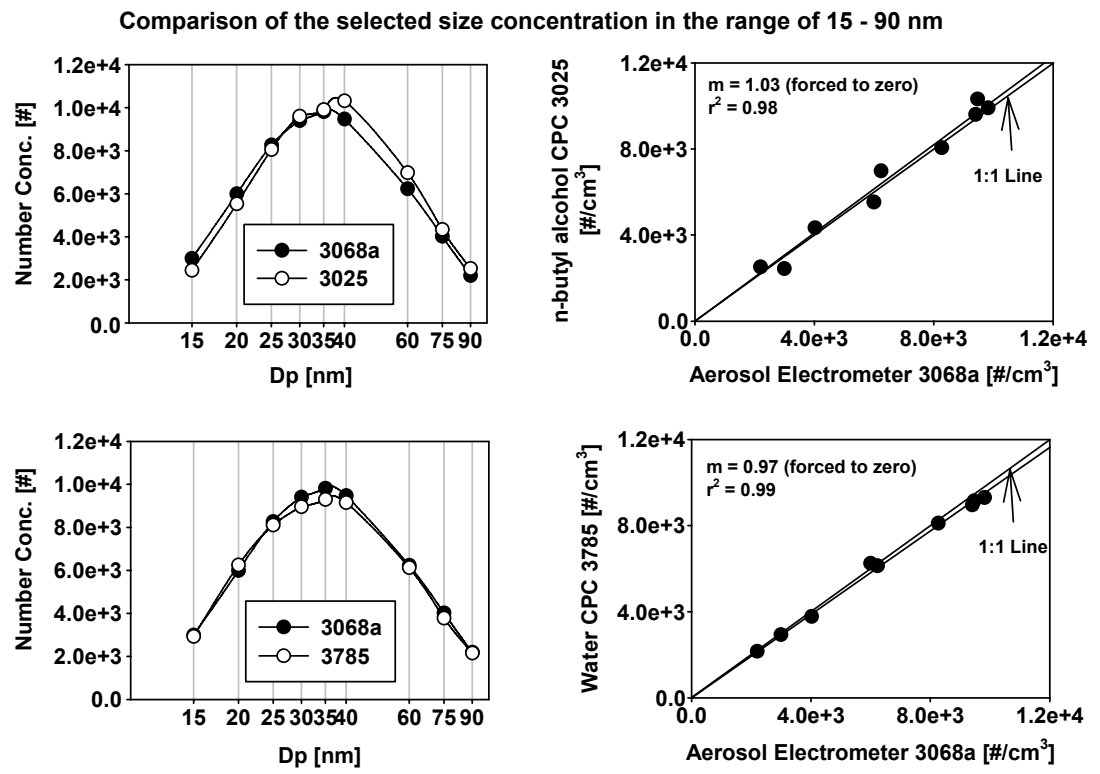

(b)
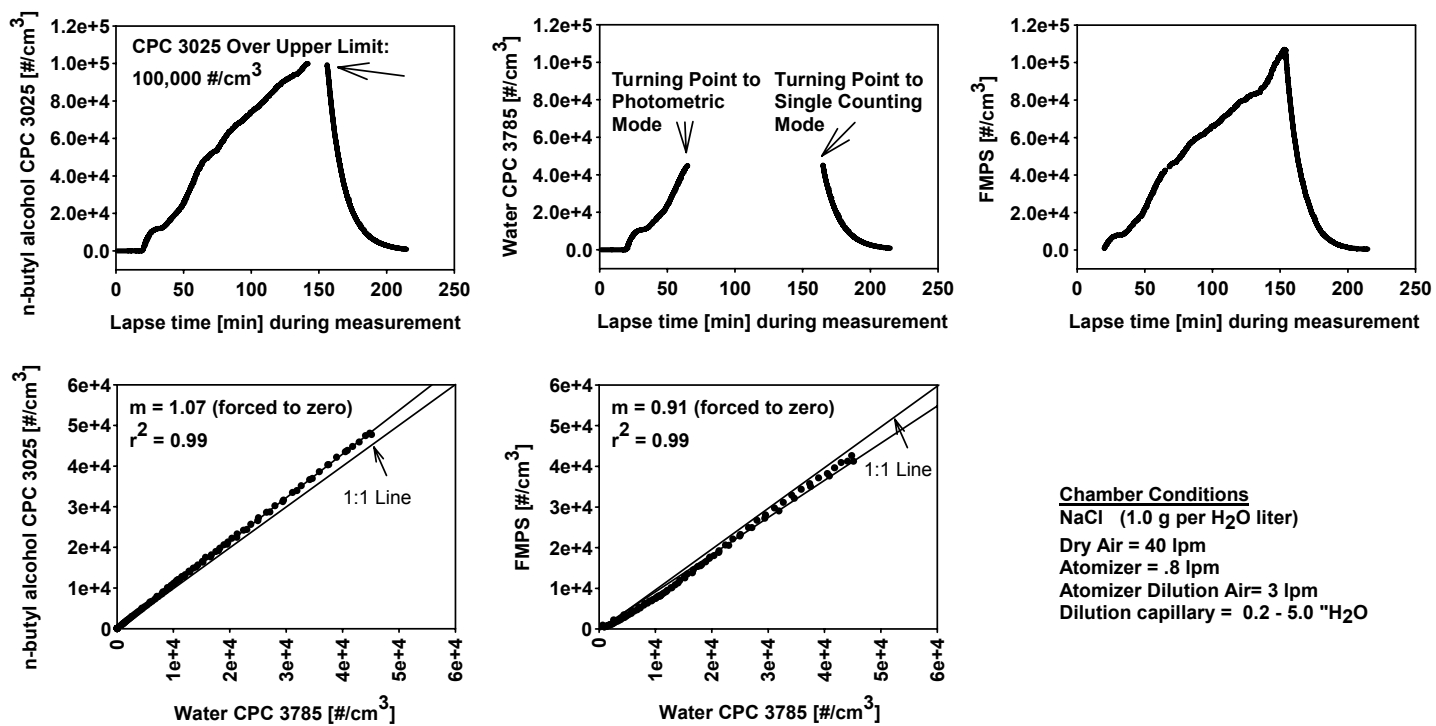

Fig. 5. (a) Intercomparison of n-butyl alcohol based CPC (CPC 3025), water based CPC (CPC 3785), and Aerosol Electrometer $3068 \mathrm{a}$ in the range of $15 \sim 90 \mathrm{~nm}$. (b) Intercomparison of total number concentrations by $\mathrm{n}$-butyl alcohol based CPC (CPC 3025), water based CPC (CPC 3785), and Fast Mobility Particle Sizer (FMPS).

Fig. 5 shows intercomparison of n-butyl alcohol based CPC (CPC 3025), water based CPC (CPC 3785), and Aerosol Electrometer 3068a in the range of $15 \sim 90 \mathrm{~nm}$ and intercomparison of total number concentrations by n-butyl alcohol based CPC (CPC 3025), water based CPC (CPC 3785), and FMPS. To quantify the comparison for these instruments, number concentration data are plotted on pair-wise 

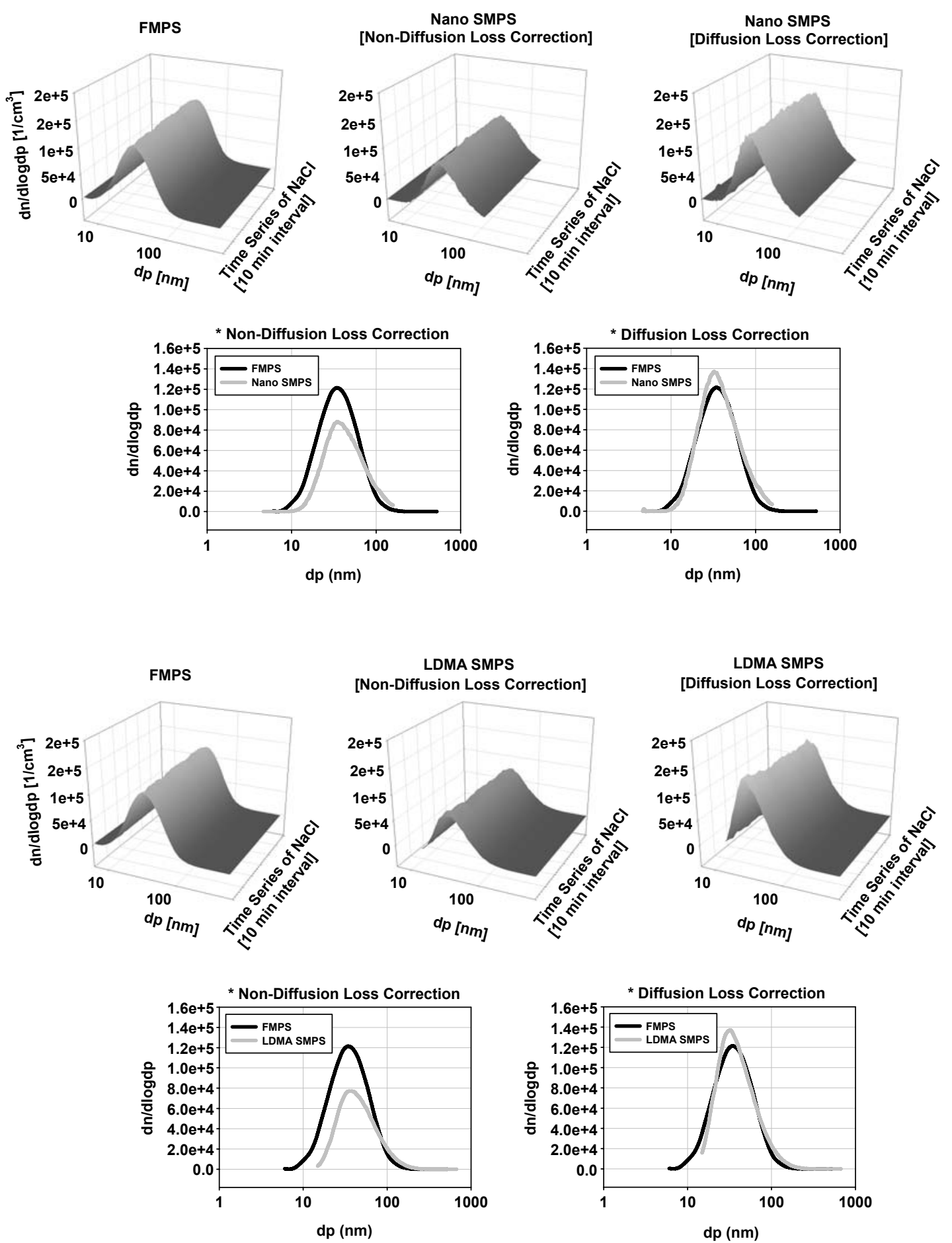

Fig. 6. Size distribution comparisons of the Nano and Long DMA Scanning Mobility Particle Sizer (Nano SMPS and LDMA SMPS) related to the Particle Diffusion Losses and Fast Mobility Particle Sizer Spectrometer (FMPS). 
scatter graphs, and the correlation explored using a least square linear regression analysis. The data are averaged on a common one minute time basis. Note that the number concentrations of water based CPC (CPC 3785) only captured at the single counting mode are compared. Fig. 5(a) and (b) shows these scatter plots for each pair of continuous instruments. In each graph the one-to-one line, the overall linear regression fit (with the intercept fixed at $(0,0)$ ), the slope of the regression with coefficient uncertainties calculated at $95 \%$ confidence intervals, and the values of $\mathrm{r}^{2}$ are given. The regressions are compared, but the differences are very modest, and not statistically significant between instruments within $10 \%$ differences. This comparison indicates that the major differences between Nano \& LDMA SMPS and FMPS are not the instrument efficiency itself.

The 3 min averaged Nano SMPS $(6 \sim 156 \mathrm{~nm})$, LDMA SMPS (14.9 173 nm), and FMPS (6 523 $\mathrm{nm})$ data are compared with and without diffusion loss correction for a targeted number concentration by the generation systems for aerosols in Fig. 6. This analysis demonstrates the effect of recalculating the data to account for diffusion losses. For the generated $\mathrm{NaCl}$ in Fig. 6, while the average number size distribution has a peak with about $1.2 * 10^{5} \mathrm{dn} / \mathrm{dlogdp}$ $\left(1 / \mathrm{cm}^{3}\right)$ at about $34 \mathrm{~nm}$ by FMPS, Nano SMPS distributions without diffusion loss correction shows a relatively much lower concentration of $8.8 * 10^{4} \mathrm{dn} /$ $\operatorname{dlogdp}\left(1 / \mathrm{cm}^{3}\right)$ at approximately $35 \mathrm{~nm}$. When corrected for diffusion loss, almost same size distribution, but rela-tively higher number concentrations are observed with about $1.4 * 10^{5} \mathrm{dn} / \mathrm{d} \operatorname{logdp}\left(1 / \mathrm{cm}^{3}\right)$ at about $35 \mathrm{~nm}$. The comparisons of the LDMA SMPS and FMPS present the similar to comparisons of the Nano SMPS and FMPS as shown in Fig. 6. In addition, compared number concentrations at a range of measured sizes show the good agreements between FMPS and SMPS with the diffusion loss correction.

Fig. 7 shows time series of the total number concentrations of the Nano SMPS and LDMA SMPS with and without the diffusion loss correction, FMPS, and n-butyl alcohol based CPC (CPC 3025). We performed the pairwise correlations, which provide insight into the range of each measurement, allow

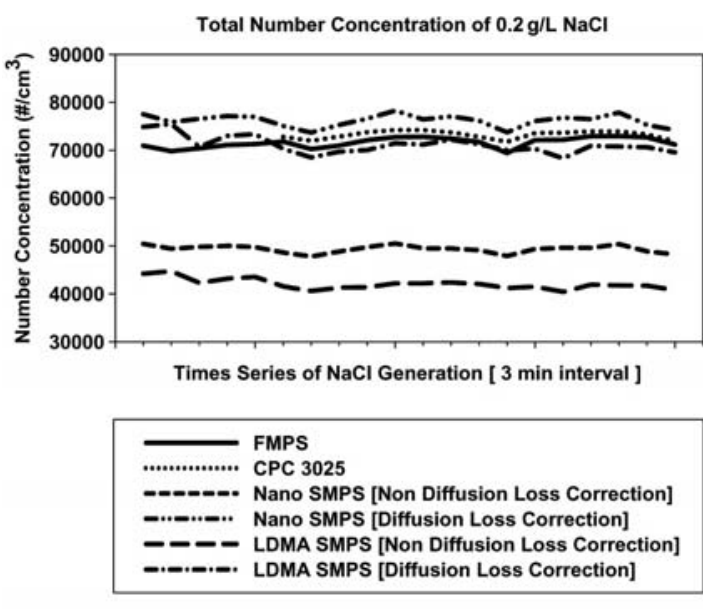

Fig. 7. Time series of the measured total number concentrations of the Nano and Long DMA Scanning Mobility Particle Sizer (Nano SMPS and LDMA SMPS) related to the Particle Diffusion Losses, Fast Mobility Particle Sizer Spectrometer (FMPS), and n-butyl alcohol based CPC (CPC 3025).

Table 2. Slope Comparisons of total number concentrations of the Nano and Long DMA Scanning Mobility Particle Sizer (Nano SMPS and LDMA SMPS) related to the Particle Diffusion Losses, Fast Mobility Particle Sizer Spectrometer (FMPS), and n-butyl alcohol based CPC (CPC 3025).

\begin{tabular}{|c|c|c|}
\hline Slope & FMPS & CPC 3025 \\
\hline Nano SMPS & 0.69 & 0.67 \\
\hline Nano SMPS DLC ${ }^{(1)}$ & 1.06 & 1.04 \\
\hline LDMA SMPS & 0.59 & 0.57 \\
\hline LDMA SMPS DLC $^{(2)}$ & 0.99 & 0.96 \\
\hline
\end{tabular}

${ }^{(1)}$ Nano SMPS DLC [Diffusion Loss Correction]

${ }^{(2)}$ LDMA SMPS DLC [Diffusion Loss Correction]

comparisons between the instruments, and demonstrate the effect of recalculating the data to account for diffusion loss. Table 2 shows the summarized slopes by pairwise correlation analysis for n-butyl alcohol based CPC (CPC 3025), FMPS, and SMPS. The SMPS number concentration with diffusion loss correction and the CPC \& FMPS number concentration agree well when the diffusion loss correction is applied to the data, statistically significant increases (closer to 1) in the slope with linear regression slopes of 0.99 and 1.06 (forced to zero). This is a strong 
Table 3. The United State of America-Federal Environmental Statues (Source: Clakson, Kenneth et al., West Business Law, p.827).

\begin{tabular}{|c|c|c|}
\hline Popular name & Purpose & Statute reference \\
\hline $\begin{array}{l}\text { Rivers and Harbors Appropriation } \\
\text { Act (1899) }\end{array}$ & $\begin{array}{l}\text { To prohibit ships and manufacturers from discharging and } \\
\text { depositing refuse in navigable waterways }\end{array}$ & 33 U.S.C $\$ 401 \sim 418$ \\
\hline $\begin{array}{l}\text { Federal Insecticide, Fungicide, and } \\
\text { Rodenticide Act (FIFRA) (1947) }\end{array}$ & To control the use of pesticides and herbicides & 7 U.S.C $\$ 136 \sim 136 y$ \\
\hline $\begin{array}{l}\text { Federal Water Pollution Control Act } \\
\text { (FWPCA) (1948) }\end{array}$ & $\begin{array}{l}\text { To eliminate the discharge of pollutants from major } \\
\text { sources into navigable waters }\end{array}$ & 33 U.S.C. $\$ 1251 \sim 1378$ \\
\hline Atomic Energy Act (1954) & To limit environmental harm from the private nuclear industry & 42 U.S.C. $\$ 2011 \sim 2297 g-4$ \\
\hline Clean Air Act (1963) & To control air pollution from mobile and stationary source & 42 U.S.C. $\$ 7401 \sim 7671 q$ \\
\hline $\begin{array}{l}\text { National Environmental Policy Act } \\
\text { (NEPA) (1969) }\end{array}$ & To limit environmental harm from federal government activities & 42 U.S.C. $\$ 4321 \sim 4370 d$ \\
\hline $\begin{array}{l}\text { Marine Protection, Research, and } \\
\text { Sanctuaries Act (Ocean Dumping } \\
\text { Act) of } 1972\end{array}$ & $\begin{array}{l}\text { To regulate the transporting and dumping of material into } \\
\text { ocean waters }\end{array}$ & 16 U.S.C. $\$ 1401 \sim 1445$ \\
\hline Noise Control Act (1972) & $\begin{array}{l}\text { To regulate noise pollution from transportation and } \\
\text { nontransportation sources }\end{array}$ & 42 U.S.C. $\$ 4901 \sim 4918$ \\
\hline Endangered Species Act (1973) & To protect species that are threatened with extinction & 16 U.S.C. $\$ 1531 \sim 1544$ \\
\hline Safe Drinking Water Act (1974) & To regulate pollutants in public drinking water systems & 42 U.S.C. $\$ 300 f$ to $300 j-25$ \\
\hline $\begin{array}{l}\text { Resource Conservation and } \\
\text { Recovery Act (RCRA) (1976) }\end{array}$ & To establish standards for hazardous waste disposal & 42 U.S.C. $\$ 6901 \sim 6986$ \\
\hline Toxic Substances Control Act (1976) & To regulate toxic chemicals and chemical compounds & 15 U.S.C. $\$ 2601 \sim 2692$ \\
\hline $\begin{array}{l}\text { Comprehensive Environmental } \\
\text { Responses, Compensation, and } \\
\text { Liability Act (CERCLA) (1980) }\end{array}$ & To regulate the clean-up of hazardous waste-disposal sites & 42 U.S.C. $\$ 9601 \sim 9675$ \\
\hline $\begin{array}{l}\text { Low Level Radioactive Waste } \\
\text { Policy Act (1980) }\end{array}$ & $\begin{array}{l}\text { To assign to the states responsibility for nuclear power } \\
\text { plants' low-level radioactive waste }\end{array}$ & 42 U.S.C. $\S 2021 b \sim 2021 j$ \\
\hline Nuclear Waste Policy Act (1982) & $\begin{array}{l}\text { To provide for the designation of a permanent radioactive } \\
\text { waste-disposal site }\end{array}$ & 42 U.S.C. $\$ 10101 \sim 10270$ \\
\hline Oil Pollution Act (1990) & $\begin{array}{l}\text { To establish liability for the clean-up of navigable waters } \\
\text { after oil-spill disasters }\end{array}$ & 33 U.S.C. $\$ 2701-2761$ \\
\hline
\end{tabular}

indication that applying the diffusion loss correction yields a truer representation of the ambient particle concentrations.

Thus, the diffusion loss correction affects both the absolute values of the particle concentrations and the basic shape of the size distribution. These results show that diffusion loss correction is always necessary for SMPS data, specially having higher concentrations in smaller size particles. When the diffusion loss correction is applied to the data, it yields statistically significant differences. This is a strong indication that applying the diffusion loss correction yields a representation of the ambient particle concentrations.

\section{SUMMARY AND SUGGESTIONS}

Understanding the role of nanoparticles is of importance in aerosol chemistry and dynamics such as formation and growth. With potential hazards of nanoparticles will require the ability to determine not only their chemical nature but also their size, shape, and number. However, accurate measurements of size distributions inclusive of particles in ultrafine size range are a challenge due to expected losses by diffusions. We analyzed the data using the diffusion loss correction for the sampling lines and Scanning Mobility Particle Sizer (SMPS) to obtain concentrations and size distributions. As expected, this correc- 
tion makes a large difference for any measurement conditions with high numbers of particles smaller mobility size. As compared to Fast Mobility Particle Sizer Spectrometer (FMPS), and n-butyl alcohol based CPC (CPC 3025), the diffusion loss corrections for the Nano and LDMA SMPS yield a required illustration of the ambient particle concentrations.

\section{IMPLICATIONS: Direct revelation mechanism as enforcement}

The United State EPA(US EPA) attempts to update pollution-control standards when new scientific information becomes available. Although the US EPA sets primary and secondary levels of ambient standards (the maximum levels of certain pollutants and the states formulate plans to achieve those standards), Section 112 of the Clean Air Act (CAA) requires the EPA to identify toxic air pollutants that cause serious illness or death to humans (42 U.S.C. $\$ 7412(b)$ : Section in hazardous Air Pollutants). The Clean Air Act sets 4 types of air quality goals; (1) to establish national ambient air quality standards(NAAQS), (2) not to deteriorate in those areas that meet the national ambient air quality standards already, (3) to require the natural visibility to be preserved within major parks, and (4) to let EPA establish emission standards to protect public health from hazardous air pollutants. The act requires the US EPA to establish standards to install maximum achievable control technology (MACT) to control emissions of toxic substances. Even though the Act establishes control standards through state implementation plan, technological control and mobile-source controls set by EPA, there leaves still room for improvement because new sources or pollutants comes forth into the air as time goes. Enforcement mechanisms under the Clean Air Act included administrate penalties, orders issued by the administrator of the US EPA, and criminal actions brought by the U.S. Attorney General, including fines of $\$ 1,000,000$ for each violation and/ or imprisonment of up to 15 years in cases where one knowingly releases hazardous air pollutants into the ambient air (Table 3) (Clarkson et al., 1998).
Classical concept of enforcement mechanism developed by Hurwicz and Marschak (1985) stated that "what the competitive (or price) mechanism achieves cannot be achieved at a lower informational cost," which means without development of measurement technology or information technology, optimal market condition cannot be attained, but there still lies incentives to hide their pollutant emitting behavior and evade regulations. When the mechanism, per se, is designed to give incentives and economic benefits to those who hide their actual amount of pollutant emission, enforcement mechanisms by themselves cannot be valid completely, only to increase the possibility of bribing or lobbying motivations. Enforcement mechanisms themselves are not sufficient for economic agents to keep and follow the environment related rules unless accuracy guaranteed measurement technology is equipped with the enforcement mechanism. In this point, the Act, amended in 1990, provides "best available control technology (BACT)" and "lowest achievable emission rate (LAER)" standards to regulate before construction of major sources of emissions.

The National Environmental Policy Act of 1969 (NEPA) requires all federal agencies to prepare a detailed Environmental Impact Statement (EIS) whenever the agency proposes legislation, recommends any actions or undertakes any activities that may affect the environments. Given the substantial data gathering necessary for successful compliance with the prerequisites of an EIS, many agencies have tried to exempt themselves from having to prepare this statements. It is nearly impossible to gauge with precision the so-called "threshold levels" of air pollution. Regulators therefore are relegated to setting exposure levels that kick in only when demonstrable adverse effects already have occurred. The CAA, which focused on multistate air pollution and provided assistance to states, and its amendments reflect complexities the ever-expanding recognition of the health risks associated with pollution, rapidly changing technologies, a veritable explosion of scientific data relating to air pollution, and industry resistance to policymakers attempts to redress the problem.

Identifying the Nano size particles is getting of 
great concern due to their chemical and physical behaviors. Recently their anthropogenic sources related to combustion sources could be related to human health rather than nature sources such as nucleation (gas to particle conversion) due to their unknown chemical structure and toxicity. However there is no statute, certainly need to be specified associated with anthropogenic sources. In this study, hereafter, a possibility of establishing direct revelation mechanism as enforcement will be required as the first. Direct revelation mechanism (Garcia, 2005; Marschak, 1985) is a mechanism that leads economic agents by themselves to true reporting behavior even though they got an option of no-reporting or of false reporting. To attain direct revelation mechanisms in action for such societal incentives as public health and ambient air quality, technological development of accurate measurement with construction of new sources of emission is required. Accurate measurement such as diffusion loss corrections associated with size distributions and number concentrations in ultrafine particles (as shown here), in line with the enforcement mechanisms, can certainly contribute to ensure compliance mechanism, which will be designed to strengthen the environmental integrity.

\section{ACKNOWLEDGMENTS}

We thank Wei-Nai Chen (Research Center for Environmental Changes, Academia Sinica, Taiwan) for assistance with the laboratory CPC comparison analysis, Olga Hogrefe for the SMPS setup, Brian Frank for the FMPS setup, James Schwab, and Garland Lala (Atmospheric Sciences Research Center, University at Albany, State University of New York, Albany, NY 12203, USA) for helpful discussions.

\section{REFERENCES}

Birmili, W., F. Stratmann, A. Wiedensohler, D. Covert, L.M. Russell, and O. Berg (1997) Determination of differential mobility analyzer transfer functions using identical instruments in series, Aerosol Sci. Technol., 27, 215-223.
Brockman, J.E. (2001) Sampling and transport of aerosols; in aerosol measurement: principles, techniques, and applications, $2^{\text {nd }}$. Edition, ed. P.A. Baron \& K. Willeke. John Wiley \& Sons, NY.

Chen, D.-R., D.Y.H. Pui, D. Hummes, H. Fissan, F.R. Quant, and G.J. Sem (1998) Design and evaluation of a nanometer aerosol differential mobility analyzer (Nano-DMA), J. Aerosol Sci., 29, 497509.

Clarkson, K.W., R.L. Miller, G.A. Jenz, and F.B. Cross (1998) West business law, p. 827.

Dal Maso, M., M. Kulmala, I. Riipinen, R. Wagner, T. Hussein, P.P. Aalto, and K.E.J. Lehtinen (2005) Formation and growth of fresh atmospheric aerosols: eight years of aerosol size distribution data from SMEAR II, Hyytiälä, Finland, Boreal Environ. Res., 10, 323-336.

Desantes, J.M., V. Bermudez, J.M. Garc, and E. Fuentes (2005) Effects of current engine strategies on the exhaust aerosol particle size distribution from a Heavy-Duty Diesel Engine, J. Aerosol Sci., 36, 1251-1276.

Garcia, D. (2005) Monotonicity in direct revelation mechanisms, J. Econ. Lett., 88, 21-26.

Frank, B.P., S. Saltiel, O. Hogrefe, J. Grygas, and G.G. Lala (2008) Determination of mean particle size using the electrical aerosol detector and the condensation particle counter: comparison with the scanning mobility particle sizer, J. Aerosol Sci., 39, 19-29.

Gormley, P.G. and M. Kennedy (1949) Diffusion from a stream flowing through a cylindrical tube, Proc Ir Acad, 52A, 163-169.

Hinds, W.C. (1982) Aerosol technology: Properties, Behavior, and Measurement of Airborne Particles, John Wiley \& Sons, NY.

Hogrefe, O., G.G. Lala, B.P. Frank, J.J. Schwab, and K.L. Demerjian (2006) Field evaluation of a TSI model 3034 scanning mobility particle sizer in New York City: Winter 2004 intensive campaign, Aerosol Sci. Technol, 753-762.

Hurwicz, L. and T. Marschak (1985) Discrete allocation mechanism: Dimensional requirements for resource-allocation mechanisms when outcomes are unbounded, J. Complexity, 1, 264-303.

Jeong, C.-H., G.J. Evans, P.K. Hopke, D. Chalupa, and M.J. Utell (2006) Influence of atmospheric dispersion and new particle formation events on 
ambient particle number concentration in rochester, United States, and Toronto, Canada, J. Air Waste Manage. Assoc., 56, 431-443.

Jeong, C.-H., P.K. Hopke, D. Chalupa, and M. Utell (2004) Characteristics of nucleation and growth events of ultrafine particles measured in rochester, NY, Environ. Sci. Technol., 38, 1933-1940.

Kim, Y. and K.H. Ahn (2005) Monitoring of airborne fine particle using SMPS in Ansan Area, 2005, J. Korean Soc. Atmos. Environ., 21(3), 295-301.

Kulmala, M., H. Vehkamaki, T. Petaja, M. Dal Maso, A. Lauri, V.M. Kerminen, W. Birmili, and P.H. McMurry (2004) Formation and growth rates of ultrafine atmospheric particles: a review of observations, J. Aerosol Sci., 35, 143-176.

Lee, J.W., H.S. Kim, and Y.I. Jeong (2006) Effects of particle measuring conditions on diesel nanoparticles distribution, 2006, J. Korean Soc. Atmos. Environ., 22(5), 653-660.

Lee, Y.G., H.W. Lee, M.S. Kim, C.Y. Choi, and J. Kim (2008) Characteristics of particle formation events in the coastal region of Korea in 2005, Atmos. Environ., 42, 3729-3739.

Marschak, T. (1985) Organization design, handbook of Mathematical Economics, 3, pp. 1359-1438.

Park, K., G. Cho, and J. Kwak (2009) Development of an aerosol focusing-laser induced breakdown spectroscopy (Aerosol Focusing-LIBS) for determination of fine and ultrafine metal aerosols, Aerosol Sci. Technol., 43(5), 375-386.

Qian, S., H. Sakurai, and P.H. McMurry (2007) Characteristics of regional nucleation events in urban east
St. Louis, Atmos. Environ., 41, 4119-4127.

Reineking, A. and J. Porstendörfer (1986) Measurements of particle loss functions in a differential mobility analyzer (TSI, Model 3071) for different flow rates, Aerosol Sci. Technol., 5, 483-486.

Rodrigue, J., M. Ranjan, P.K. Hopke, and S. Dhaniyala (2007) Performance comparison of scanning electrical mobility spectrometers, Aerosol Sci. Technol., 41, 360-368.

Stanier, C.O., A.Y. Khlystov, and S.N. Pandis (2004) Nucleation events during the pittsburgh air quality study: Description and relation to key meteorological, gas phase, and aerosol parameters, Aerosol Sci. Technol., 38, 253-264, 2004.

TSI, Inc. (2006) Scanning mobility particle sizer (SMPS) spectrometer diffusion loss correction, application note SMPS-001. Shoreview, MN.

Wang, J., R.C. Flagan, and J.H. Seinfeld (2002) Diffusional losses in particle sampling systems containing bends and elbows, J. Aerosol Sci., 33, 843-857.

Watson, J.G., J.C. Chow, K. Park, and D.H. Lowenthal (2006) Nanoparticle and ultrafine particle events at the fresno supersite, J Air Waste Manage., 56, 417-430.

Watson, J.G., J.C. Chow, D.H. Lowenthal, and K.L. Magliano (2008) Estimating aerosol light scattering at the fresno supersite, Atmos. Environ., 42, 1186-1196.

Woo, D., S. Lee, G. Bae, and T. Kim (2008) Comparison of ultrafine particles monitored at a roadside using an SMPS and a TR-DMPS, J. Korean Soc. Atmos. Environ., 24(4), 404-414. 